УДК 316.776 .32

\section{Юшкина Надежда Александровна}

зам. директора Центра изучения российской элиты, ст. преподаватель, ФГБОУ ВО «Государственный университет управления», г. Москва, Российская Федерация

ORCID: 0000-0002-4157-1921

e-mail:4454508@gmail.com

\section{Nadezhda A. Yushkina}

Deputy Director of the Russian Elite Research Centre, Senior Lecturer, State University of Management, Moscow, Russia

ORCID: 0000-0002-4157-1921

e-mail:4454508@gmail.com
DOI 10.26425/1816-4277-2022-1-188-196

\section{ЭЛЕКТОРАЛЬНЫЙ ПОТЕНЦИАЛ ПУБЛИЧНЫХ ПОЛИТИКОВ В СОЦИАЛЬНЫХ СЕТЯХ}

\begin{abstract}
Аннотация. Объектом исследования являются представители российской политической элиты и их электорат в сочиальных сетях. Цель исследования - оценка влияния на электоральный потенциал политиков их интернет-коммуникаций со своей аудиторией. Анализировались основные количественные показатели присутствия и активности российских публичных политиков в Facebook, Instagram и Yоитиbe, успешные формы взаимодействия между представителями власти и обществом, индексы популярности, активности, лояльности аудитории, а также визуальные особенности контента аккаунтов. Оценивалась обратная связь в аккаунтах действующих политиков, в том числе содержащая критический дискурс. По итогам исследования сделаны выводы, что создание полноценного канала обратной связи с потенциальным электоратом положительно влияет на образ публичного политика, позволяет уменьшать количество обратной связи с негативными комментариями, является успешной формой взаимодействия политика с электоратом и повышает его электоральный потенциал. Вместе с тем российские политики недостаточно готовы к налаживанию коммуникации с потенцииальным электоратом через социальные сети.
\end{abstract}

Ключевые слова: публичный политик, органы власти, элиты, сочиильные сети, ичифровая сфера, электоральный потенциал, Интернет, государство, власть, политическая коммуникация

Для цитирования: Юшкина Н.А. Электоральный потенциал публичных политиков в социальных сетях// Вестник университета. 2022. № 1. С. 188-196.

\section{PUBLIC POLITICIANS ELECTORAL POTENTIAL IN SOCIAL MEDIA}

Abstract. The object of the study are representatives of Russian political elite and their electorate in social networks. The aim of the study is to assess the impact on the electoral potential of politicians of their online communications with their audiences. The main quantitative indicators of the presence and activity of the Russian public politicians on Facebook, Instagram and Youtube, successful interaction forms between government representatives and the society, indexes of popularity, activity, audience loyalty, as well as visual features of the accounts' content were analysed. Feedback in the accounts of current politicians was assessed, including containing critical discourse. According to the results of the study, the author concluded that the creation of a full-fledged feedback channel with a potential electorate positively affects the image of a public politician, allows reducing the feedback amount with negative comments, is a successful interaction form between a politician and the electorate and increases his electoral potential. However, the Russian politicians are not sufficiently prepared to establish communication with the potential electorate via social media.

Keywords: public politician, authorities, elites, social networks, digital sphere, electoral potential, Internet, state, government, political communications

For citation: Yushkina N.A. (2022) Public politicians electoral potential in social media. Vestnik universiteta, no. 1 , pp. $188-196$. DOI: $10.26425 / 1816-4277-2022-1-188-196$

\title{
Введение
}

С ростом цифровизации общества способы и модели политической коммуникации трансформируются существенным образом, что оказывает непосредственное влияние на всю систему государственного управления и способствует выходу публичной политики за пределы традиционного политического пространства. Интернет и социальные сети становятся универсальным способом структурирования современного социального пространства, а «виртуальная активность трансформируется в реальный политический дискурс,

(с) Юшкина Н.А., 2022.

Статья доступна по лицензии Creative Commons «Attribution» («Атрибуция») 4.0. всемирная (http://creativecommons.org/licenses/by/4.0/).

(C) Yushkina N.A., 2022.

This is an open access article under the CC BY 4.0 license (http://creativecommons.org/licenses/by/4.0/).

(c) (i) 
становясь полноправным элементом политико-коммуникационной среды» [2, с. 177-178] Виртуальное социальное пространство сегодня рассматривается не просто как коммуникативная среда, но и как пространство реализации публичной политики. Возникают и получают развитие новые, онлайновые формы политического дискурса и механизмы взаимосвязи власти и общества [5].

Подобные механизмы коммуникации и взаимодействия позволяют общественности найти собственные варианты политического представительства, которые совпадали бы с их нынешними интересами, но сегодня еще не являются частью уже устоявшейся системы. Социальные сети являются прекрасной платформой для создания полноценного канала обратной связи между властью и обществом. Люди голосуют в сети лайками и репостами [6, с. 28]. Выстраивание диалога политика с подписчиками как потенциальными избирателями в дальнейшем влияет на их электоральное поведение и помогает политикам наращивать свой электоральный потенциал. Исследования показали, что участие самого кандидата в дискуссиях в социальных сетях ведет к увеличению количества возможных методов взаимодействия между общественностью и предвыборной кампанией [8].

Коммуникации в социальных сетях в еще большей степени актуальны для молодежной части аудитории, которая погружена в социальные сети с детства, предпочитает все больше получать из них информацию, касающуюся большинства интересующих ее сфер, общественно-политическая не является исключением. Более того, наше исследование показало, что интерес к этой сфере у молодежи присутствует, но информацию о ней молодые люди в большей степени получают от блогеров, чем от действующих политиков. Это обусловлено несколькими факторами, отметим в этой статье лишь основной, с которого надо начинать. Если политик не присутствует в социальных сетях, не открыт для такого типа общения, которое адекватно воспринимается молодежью, то он существует как бы параллельно с молодежной аудиторией, никак не влияя на ее политическое сознание. Для этой потенциальной части электората он как бы не существует. Чтобы получить поддержку в молодежной среде и быть одобряемым, иметь возможность переизбрания, избежать активных протестных настроений, лидер должен уметь говорить с молодежной аудиторией на одном языке, соответствовать образу эффективного политика, существующему в сознании молодежи [3].

Несмотря на обилие книг и статей, посвященных взаимодействию власти и общества в виртуальном пространстве, повсеместному процессу цифровизации, мы видим несовершенство используемых технологий и теорий, недостаточность раскрытия социально-политических тем российскими публичными политиками, отсутствие проработанных механизмов в публичном политическом пространстве.

Для того, чтобы ответить на вопросы, почему лишь некоторым политикам удается успешно доносить до людей смысл происходящих процессов, свою позицию, вовлекать миллионы в политические процессы и многократно наращивать свой электоральный потенциал, а остальные делают попытки, которые не приводят их к росту аудитории и расширению влияния, мы провели социологическое исследование, которое начали с анализа присутствия российских публичных политиков в социальных медиа и измерения их активности, а также особенностей налаживания обратной связи с потенциальным электоратом.

Мы изучили и подвергли анализу социальные площадки действующих на момент сбора данных публичных политиков, для которых имеет ключевое значение умение налаживать контакт с потенциальным электоратом для того, чтобы разъяснять государственную политику и значение проводимых реформ и законопроектов, показывать, как государство заботится об интересах своих граждан и как следствие, наращивать свой электоральный потенциал. Поэтому в нашем исследовании были проанализированы сетевые коммуникации депутатов и сенаторов Федерального Собрания Российской Федерации (далее - ФС РФ), а также глав регионов, которые имеют аккаунты хотя бы в одной из исследуемых нами популярных социальных сетей, для того, чтобы выявить среди них тех, кто успешно нарастил электорат и реализовал свой коммуникативный потенциал в сетях, а также тех, кому не удается достичь значимых результатов вовлечь и нарастить аудиторию. Сбор данных происходил в сентябре 2021 г. накануне и в процессе выборов в Государственную Думу Российской Федерации (далее - ГД РФ).

\section{Методы и материалы}

Задача исследования заключалась в том, чтобы выявить основные показатели присутствия и активности публичных политиков в социальных сетях и их влияние на электоральный потенциал политиков, определить наиболее успешные формы взаимодействия между политиками и обществом посредством социальных 
сетей, ответить на вопросы, используют ли российские публичные политики социальные сети как инструмент для наращивания электорального потенциала и готовы ли они к коммуникациям с потенциальными избирателями в социальных сетях.

Объектом данного исследования стали представители политической элиты: депутаты Государственной Думы VII созыва, члены Совета Федерации ФС РФ, а также главы российских регионов. Предметом исследования были аккаунты и сетевая активность в популярных социальных сетях действующих публичных политиков.

Проведен количественный и сравнительный анализ статистики аккаунтов и коммуникативных процессов в трех популярных социальных сетях - Facebook, Instagram и Youtube. В выборку вошли все представленные в исследуемых социальных сетях аккаунты публичных политиков, действующие на момент сбора данных (сентябрь 2021 г.) - представителей ФС РФ и глав регионов Российской Федерации. Общая численность генеральной совокупности составила 694 человека. Проведен анализ фактического присутствия публичных политиков в исследуемых социальных сетях. Составлена база данных аккаунтов и база данных количественных показателей статистики аккаунтов публичных политиков по трем социальным сетям, в которую вошли 650 аккаунтов.

Далее, анализ выполнялся с помощью мониторинга аккаунтов публичных политиков в социальных сетях и фиксирования основных индикаторов. Анализировались количественные показатели, были составлены специально разработанные для целей проекта индексы популярности, активности, присутствия в социальных сетях, лояльности аудитории, фиксировались особенности обратной связи с аудиторией, а также визуальные особенности контента аккаунтов.

\section{Основные результаты}

Присутствие политиков в исследуемых социальных сетях оказалось неравномерным. Во все трех категориях политиков присутствуют те, кто вообще не зарегистрирован ни в одной из трех исследуемых социальных сетях. По этому показателю лидируют представители Совета Федерации РФ 47,3\% не имеют аккаунтов ни в Instagram, ни на Facebook, ни в Youtube. Почти половина сенаторов не готовы налаживать общение с потенциальным электоратом через популярные социальные сети. Индекс присутствия в социальных сетях, который рассчитывался, как отношение всех аккаунтов группы к численности группы, у глав регионов самый высокий $(1,74)$, у депутатов ГД РФ чуть ниже $(1,64)$, у сенаторов он оказался значительно ниже $(0,82)$. Самыми открытыми социальным сетям оказались главы российских регионов, лишь 4,7 \% из них не имеют аккаунтов в исследуемых нами социальных сетях. Наибольшее количество публичных политиков имеют аккаунты в социальной сети Instagram. В этой сети также сосредоточены аккаунты с наибольшим количеством подписчиков и высоким электоральным потенциалом. По совокупному количеству подписчиков в исследуемых социальных сетях перешли планку в миллион подписчиков лишь два политика: мэр Москвы С. С. Собянин (1 047869 чел.) и депутат ГД РФ А.С. Делимханов (1 700971 чел.), оба получили основной электоральный потенциал в Instagram. Хуже всего публичные политики оказались представлены на платформе Youtube: лишь 18,7 \% имеют там аккаунты, 39 \% из которых оказались «заброшенными» на момент сбора данных, то есть активность в них была остановлена как минимум за три месяца до начала сбора данных.

Однако одно лишь присутствие в социальных сетях еще не говорит о готовности работать и налаживать в них коммуникации. Группа может иметь аккаунты, но лишь формально и не использовать их, либо использовать в личных целях. При расчете количественных показателей были выявлены «заброшенные» аккаунты. Таковыми мы считали аккаунты, публикации в которых не велись более, чем два месяца, предшествующих расчетному периоду. Работа в социальных сетях подразумевает некую регулярность и не может вестись эффективно от случая к случаю. Больше всего «заброшенных» аккаунтов оказалось у депутатов ГД РФ (18,4 \%), но это может быть связано с тем, что сбор данных проходил накануне выборов в ГД РФ и часть депутатов, которая не планировала баллотироваться на новый срок, прекратила и свою деятельность по наращиванию электорального потенциала в социальных сетях. Однако такое решение нельзя назвать эффективным, к примеру, с точки зрения политических партий, которым важно наращивать общий электоральный потенциал, особенно накануне важного политического события. Члены Совета Федерации ФС РФ имеют 8,9 \% неактивных аккаунтов, руководители регионов лишь 1\%. Закрытых от пользователей, не состоящих в друзьях у автора аккаунта, оказались $1,1 \%$ аккаунтов депутатов ГД РФ и 2,3 \% аккаунтов 
сенаторов. Такие аккаунты могут использоваться лишь в личных целях, для коммуникации со знакомыми политику людьми и не могут выполнять функции по наращиванию электорального потенциала. Ни одного закрытого аккаунта нет у глав российских регионов, что еще раз подтверждает самую высокую степень открытости этой группы публичных политиков.

Следующим важным показателем, демонстрирующим степень готовности вести регулярную работу в социальных сетях является индекс активности. Сразу отметим, что он фиксирует лишь частоту публикаций и определяется для каждой группы как отношение количества публикаций всех аккаунтов группы за изучаемый период к количеству аккаунтов в группе. Групповой индекс активности руководителей российских регионов оказался самым высоким $(1,146)$ и превысил групповой индекс активности сенаторов $(0,517)$ более, чем вдвое. Индекс активности депутатов ГД РФ составил 0,625. Результаты показателя групповой активности подтверждает и десятка политиков - лидеров по индивидуальной активности в социальных сетях. Так, в нее вощли пять руководителей регионов, четыре депутата ГД РФ и лишь один член верхней палаты парламента. Таким образом, можно подвести первый итог - наиболее открытой и активной в социальных сетях группой являются руководители российских регионов, значительно обходя представителей российского Парламента, особенно его верхней палаты. Этот вывод совпадает с выводами исследования 2019 г. [4]. Причем за прошедший период самая открытая группа, судя по всему, значительно улучшила свои показатели в социальных сетях.

Поскольку социальные медиа становятся значимой площадкой для взаимодействия с электоратом, а электоральный потенциал предполагает выявление вероятности того, что при проведении выборов данный политик получит голоса потенциальных избирателей, особо важными становятся количественные показатели, связанные с совокупным числом подписчиков и степенью их вовлеченности в коммуникативный процесс, оценкой объема и тональности обратной связи, а также анализ публикуемого политиками контента [1, с. 47-55].

Для того, чтобы оценить электоральный потенциал каждой группы, мы рассчитали групповой индекс популярности, который показал, каким объемом потенциальных избирателей обладает каждая группа. Данный показатель привязан к количеству подписчиков, отдавших свое предпочтение аккаунтам определенной группы политиков и определяется как отношение общего числа подписчиков группы к количеству аккаунтов этой группы политиков. Индекс популярности глав российских регионов $(103220,2)$ оказался почти в 7 раз выше индекса популярности депутатов ГД РФ и более чем в 15 раз превысил индекс популярности членов СФ РФ.

В отечественной социологии активно изучается тема использования властью социальных сетей, как новых форм общения с обществом. В основном, исследователи делают выводы о необходимости выстраивания диалога, налаживания обратной связи между правящими слоями и населением.

Чтобы оценить вовлеченность в коммуникативный процесс политиков и их потенциальных избирателей в социальных сетях, были рассчитаны два показателя: индекс лояльности и индекс вовлеченности. Как уже было сказано выше, аудитория социальных сетей голосует лайками. Данный вид реакции показывает одобрение подписчиками опубликованного контента, но не отражает, по каким критериям был оценен данный контент. По этому показателю можно судить о степени активности подписчиков группы. Групповой индекс лояльности определялся как отношение суммы среднего количества «лайков» в день, полученных всеми аккаунтами группы к общему числу подписчиков группы. Низкое значение этого показателя может быть связано как с низкой лояльностью подписчиков к публикуемому группой контенту, так и с большим процентом неактивных подписчиков, которые образуются в случае применения принудительны и некачественных методов привлечения подписчиков в аккаунт.

Самый низкий индекс лояльности аудитории оказался у депутатов ГД РФ $(0,0107)$, а самый высокий у глав регионов России $(0,0193)$. Это единственный количественный показатель, по которому члены Верхней палаты Парламента оказались не на последнем месте $(0,0128)$. При каких обстоятельствах могла сложиться ситуация, при которой группа, отстающая по всем предыдущим показателям, вышла на второе место по количеству одобряющих кликов аудитории. Наша гипотеза заключалась в том, что основу небольшой, но лояльной аудитории сенаторов составили друзья, знакомые и сослуживцы членов СФ РФ, которые активно проявляют себя либо из вежливости, либо из солидарности. Депутаты ГД РФ, напротив, либо публикуют некачественный и не привлекающий аудиторию контент, либо имеют в подписчиках большой процент аккаунтов, за которыми не стоят живые люди, способные производить действия в сети. Частично подтвердить или опровергнуть предположения поможет второй индекс, построенный на основе такой реакции аудитории, как комментарии. 
Следует отметить, что получить этот вид реакции от аудитории гораздо сложнее, чем предыдущий, публикация должна вызвать у них интерес и желание вступить в дискуссию. Для анализа он представляет гораздо большую ценность. Индекс заинтересованности рассчитывался, как отношение среднего числа комментариев в день в аккаунтах группы к общему числу подписчиков группы. Наибольшее значение индекса оказалось у глав российских регионов $(0,001307)$. Подписчики в аккаунтах депутатов ГД РФ комментируют их публикации значительно реже, индекс заинтересованности этой группы политиков составил 0,000728. Коммуникация ГД ФС РФ в социальных сетях инициируется с целью информирования пользователей о принятии законопроекта, но не его обсуждения. Подтверждаются выводы предыдущих исследований о том, что социальные медиа используются, главным образом, для информирования, но не задействуются их возможности для двухсторонней коммуникации с граждан [7].

Еще ниже показатель индекса у членов СФ РФ $(0,000519)$. Лояльная им аудитория не вступает в дискуссии и не проявляет интереса к публикациям этой группы политиков, что подтверждает гипотезу о «вынужденной» лояльности.

При подсчете индекса заинтересованности были исключены аккаунты политиков, которые принудительно закрыли функцию комментирования, лишив свою аудиторию возможности оставлять комментарии под публикациями и закрыв таким образом важный канал коммуникации с потенциальными избирателями. Как правило, к таким мерам политики прибегают в том случае, если комментарии содержат большое количество критики, которая зачастую может содержать крайне негативные высказывания и ненормативную лексику. Для оценки тональности обратной связи мы проанализировали, как часто публичные политики сталкиваются с критикой и на что направлен критический дискурс в аккаунтах политиков. При этом необходимо пояснить, что под критическими комментариями мы понимали высказывания с негативной оценкой, недовольством какой-либо деятельностью, выраженной в яркой и категоричной форме. Мы не относили к критическим комментариям обращения с целью получения помощи или сообщения о ситуациях, требующих вмешательства органов власти.

Сталкиваются с критикой под своими публикациями 82,2 \% глав российских регионов. Лишь 12,4 \% руководителей регионов удается вести свои аккаунты так, чтобы обходиться без критических комментариев в них. Отключили функцию обратной связи с подписчиками на момент сбора данных 5,2 \% политиков. Намного лучше обстоят дела у представителей российского Парламента: с критическими комментариями сталкивается почти вполовину меньше, чем главы регионов (37,4 \%) депутатов Нижней палаты и лишь 27,5 \% членов Верхней палаты (за период сбора данных). При этом закрывали возможность оставлять комментарии в своих аккаунтах 2,5 \% депутатов и 3,9 \% сенаторов. Мы видим, что чем более открытой в социальных сетях является группа политиков, тем больше ей приходится сталкиваться с критикой со стороны потенциальных избирателей (табл. 1).

Таблиия 1

Наличие критической обратной связи в аккаунтах публичных политиков

\begin{tabular}{|c|c|c|c|c|c|}
\hline \multirow[t]{2}{*}{ Категории политиков } & \multicolumn{2}{|c|}{$\begin{array}{c}\text { Обратная связь критиче- } \\
\text { ского содержания в аккаун- } \\
\text { тах (на период сбора } \\
\text { данных) }\end{array}$} & \multirow[t]{2}{*}{$\begin{array}{c}\text { Закрытые } \\
\text { и заброшенные } \\
\text { аккаунты }\end{array}$} & \multirow[t]{2}{*}{$\begin{array}{c}\text { Нет } \\
\text { комментариев }\end{array}$} & \multirow[t]{2}{*}{$\begin{array}{c}\text { Закрыта функция } \\
\text { комментирования } \\
\text { в аккаунте }\end{array}$} \\
\hline & присутствует & отсутствует & & & \\
\hline \multirow[t]{2}{*}{ Главы регионов $(N=97), \%$} & 70,0 & 12,0 & 8,0 & 2,0 & 5,0 \\
\hline & 72,2 & 12,4 & 8,2 & 2,1 & 5,2 \\
\hline \multirow[t]{2}{*}{ Депутаты ГД $(N=441), \%$} & 165,0 & 154 & 85,0 & 26,0 & 11,0 \\
\hline & 37,4 & 34,9 & 19,3 & 5,9 & 2,5 \\
\hline \multirow[t]{2}{*}{ Члены СФ $(N=102), \%$} & 28,0 & 44,0 & 17,0 & 9,0 & 4,0 \\
\hline & 27,5 & 43,1 & 16,7 & 8,8 & 3,9 \\
\hline
\end{tabular}

Составлено автором по материалам исследования 
Рассмотрим основную направленность критического дискурса в аккаунтах публичных политиков. При анализе критических высказываний мы условно выделили четыре основные группы направленности критики: непосредственно на автора аккаунта, на проблему, которую он поднял в публикации, на действия властей в целом и на оппонентов, которые имеют отличную от комментатора позицию по теме публикации (табл. 2). При этом в одной публикации могло содержаться одновременно несколько комментариев с разными видами негативных высказываний, все они учитывались при определении направленности дискуссии и отражались в подсчетах.

Таблица 2

\section{Направленность критического дискурса в аккаунтах публичных политиков}

\begin{tabular}{|c|c|c|c|c|c|}
\hline \multirow[t]{2}{*}{$\begin{array}{l}\text { Категории } \\
\text { политиков }\end{array}$} & \multicolumn{4}{|c|}{$\begin{array}{c}\text { Направленность критических комментариев } \\
\text { в аккаунтах политиков* }\end{array}$} & \multirow{2}{*}{$\begin{array}{l}\text { Отсутствуют } \\
\text { критические } \\
\text { комментарии }\end{array}$} \\
\hline & на автора & на проблему & на власть & на подписчиков & \\
\hline \multirow[t]{2}{*}{ Главы регионов $(N=82), \%$} & 31,0 & 72,0 & 33,0 & 2,0 & 12,0 \\
\hline & 36,6 & 87,8 & 41,4 & 2,4 & 12,4 \\
\hline \multirow[t]{2}{*}{ Депутаты ГД $(N=345), \%$} & 62,0 & 106,0 & 76,0 & 3,0 & 154,0 \\
\hline & 17,8 & 30,7 & 22,0 & 0,9 & 34,9 \\
\hline \multirow[t]{2}{*}{ Члены СФ $(N=81), \%$} & 11,0 & 18,0 & 11,0 & 0,0 & 44,0 \\
\hline & 13,6 & 22,2 & 13,6 & 0,0 & 43,1 \\
\hline
\end{tabular}

*Примечание: в одной публикации может присутствовать несколько видов критических комментариев. В подсчетах учитывались только активные аккаунты с открытой функцией обратной связи.

Составлено автором по материалам исследования

Наибольшее количество негативных высказываний в аккаунтах публичных политиков направлены на проблемы, которые затрагиваются авторами аккаунтов в публикациях либо с которыми потенциальные избиратели сталкиваются в процессе жизнедеятельности. Этот показатель может отображать не только наличие самой проблемы, но и ее значимость, релевантность для подписчиков аккаунта, а также готовность автора аккаунта освещать актуальные для потенциального электората вопросы. Данный показатель в аккаунтах глав регионов оказался почти в 3 раза выше, чем в аккаунтах российских парламентариев. На наш взгляд, это связано с тем, что большинство глав регионов в своих аккаунтах поднимают актуальные для региона вопросы и темы, что вызывает реакцию аудитории и желание дать обратную связь по предложенной теме. Такой вид критического дискурса превалирует в аккаунтах всех публичных политиков, потенциальных избирателей более всего волнуют не персоналии, а конкретные проблемы, возникающие на момент публикации у жителей определенного региона или в целом в нашей стране. Более низкий процент присутствия данного вида обратной связи в аккаунтах парламентариев может быть связан не только с отсутствием актуальной повестки в аккаунтах, но и с другой отмеченной нами тенденцией: несмотря на то, что каждый парламентарий делегируется в парламент страны от определенного региона и призван представлять, в первую очередь, свой регион, довольно большое количество депутатов и сенаторов пишут в своих аккаунтах больше о проблемах более глобальных, касающихся страны в целом либо внешнеполитической деятельности. В свою очередь, для потенциальных избирателей проблемы, которые им ближе, могут быть понятнее и актуальнее. Они в меньшей мере освещаются на федеральных телеканалах, но касаются наиболее узких слоев населения, сосредоточенных в одном регионе. Этот фактор может указывать и на актуальность и остроту для подписчиков национальной и межнациональной повестки.

Около трети комментариев, содержащих критические высказывания, были направлены на руководителей глав регионов, как авторов публикаций в своих аккаунтах. Этот показатель также оказался выше у этой категории политиков по сравнению с членами верхней и нижней палаты российского парламента. Люди больше склонны связывать наличие определенных проблем с непосредственными руководителями своих регионов, чем с людьми, которых регион и сами избиратели делегировали в парламент для представления их интересов на федеральном уровне. Это возможно из-за низкой узнаваемости парламентариев в регионах 
и недостаточным пониманием электоратом принципов работы политической вертикали. Однако, при этом в аккаунтах у 12,4 \% глав регионов за время сбора информации не было выявлено высказываний с явной негативной оценкой, или недовольством (табл. 3).

Для более полного понимания коммуникативных процессов, происходящих в аккаунтах публичных политиков, рассмотрим подробнее аккаунты политиков, которым удается практически избегать обратной связи с негативной составляющей на примере наиболее открытой группы публичных политиков - глав российских регионов. Постараемся подвергнуть анализу и определить те составляющие и особенности контента, которые могут позволять их авторам сохранять положительный либо нейтральный характер дискуссии в своих аккаунтах (см. табл. 3).

Таблица 3

Главы российских регионов, не имеющие критической обратной связи в аккаунтах

\begin{tabular}{|l|c|c|}
\hline \multicolumn{1}{|c|}{ ФИо } & Социальная сеть & Количество подписчиков аккаунта \\
\hline Азаров Дмитрий Игоревич & Instagram & 278000 \\
Артамонов Игорь Георгиевич & Instagram & 134000 \\
Бездудный Юрий Васильевич & Instagram & 2830 \\
Кадыров Рамзан Ахматович & Youtube & 69700 \\
Клычков Андрей Евгеньевич & Instagram & 85800 \\
Кувшинников Олег Александрович & Instagram & 43600 \\
Меняйло Сергей Иванович & Facebook & 9128 \\
Никитин Александр Валерьевич & Facebook & 8945 \\
Николаев Айсен Сергеевич & Youtube & 2590 \\
Носов Сергей Константинович & Instagram & 26700 \\
Темрезов Рашид Бориспиевич & Instagram & 118375 \\
Шумков Вадим Михайлович & Instagram & 76800 \\
\hline Составло & \\
\hline
\end{tabular}

Составлено автором по материалам исследования

В целом во всех представленных в таблице 3 аккаунтах политиками используются разнообразные формы подачи контента: представлены качественные фото-, видеоматериалы, в том числе отражающие красоту и самобытность регионов, главами которых являются политики. Используются форматы, отражающие приближенность к реальной жизни: «селфи» (самостоятельно сделанные фото, подчеркивающие неформальность и отсутствие посредников между главой региона и его подписчиками, фото- и видеоматериалы непосредственного участия политика в решении каких-либо задач, участия в мероприятиях. Присутствует контент, демонстрирующий близость политика к народу и озабоченность проблемами региона: личный прием граждан, беседы с населением на улицах населенных пунктов. В небольших объемах присутствует информация о личной жизни политика, позволяющая «очеловечить», приблизить к народу строгий в рабочее время образ политика (как правило, отражающая семейные ценности, приверженность к здоровому образу жизни, либо демонстрирующая личные хобби). Присутствуют публикации, вызывающие положительные, яркие, искренние эмоции: например, восхищение цветами, кадры спасения касатки, застрявшей на мели. В целом, контент вызывает положительные эмоции, обязательно присутствуют публикации, вызывающие у подписчиков чувство радости и гордости (например, за победу земляков в соревнованиях), сопричастность к добрым делам или хорошим начинаниям (призыв к участию в экологических акциях, призванных навести чистоту в регионе). Отдельное внимание уделяется особенностям региона и народов, проживающих в нем, его красотам и богатствам. Особенно хорошо это видно в аккаунте главы Чеченской республики Рамзана Кадырова в социальной сети Youtube и главы Карачаево-Черкесской республики Рашида Темрезова в социальной сети Instagram. Основными ценностями, которые заложены в контент аккаунтов политиков являются: патриотизм, ответственность, взаимопомощь, доверие, уверенность, оптимизм, уважение, человечность. 
Важной составляющей аккаунтов является отлаженная реакция государственных органов региона на обращения граждан, которые поступают в аккаунт глав регионов. На каждый вопрос или сигнал о возникшей проблеме автор комментария получает развернутый ответ от официального аккаунта государственного органа, в зону ответственности которого входит решение вопроса или проблемы подписчика. Результат такого взаимодействия виден всем подписчикам аккаунта главы региона, он удовлетворяет потребности потенциальных избирателей, демонстрирует слаженную работу ведомств региона, побуждает отвечать благодарностью за решенные проблемы. Подобная практика также способствует сближению главы региона с жителями и потенциальным электоратом в социальных сетях. Это отражается в комментариях подписчиков, которые характеризуют главу региона: «у него слова не расходятся с делом», «хороший мужик». Важно отметить, что даже сообщения о возникших проблемах и обращения с просьбой о помощи формулируются подписчиками в подчеркнуто уважительной форме. Отдельно необходимо отметить, что в аккаунтах с числом подписчиков менее 10 тыс. обратной связи в целом немного.

\section{Обсуждение результатов}

В современных реалиях присутствие в социальных сетях и коммуникации с потенциальным электоратом для публичных политиков является важным и необходимым условием, особенно для привлечения молодежной части электората. Почти половина представителей верхней палаты российского парламента оказалась не готовой налаживать коммуникации с электоратом и не имеет аккаунтов ни в одной из трех популярных социальных сетей (Insagram, Facebook, Youtube). Наиболее открытой социальным сетям группой оказались главы российских регионов. Они также имеют самый высокий индекс популярности, а значит и наибольший электоральный потенциал в социальных сетях, и опережают представителей российского парламента по показателям активности, вовлеченности аудитории в коммуникативный процесс и обратной связи с аудиторией.

Однако выявилась прямая зависимость: чем более открытой в социальных сетях является группа политиков, тем больше ей приходится сталкиваться с критикой со стороны потенциальных избирателей. Это заставляет некоторых политиков принудительно отключать функцию обратной связи в своих аккаунтах.

При анализе критических дискуссий в комментариях аккаунтов публичных политиков было выявлено четыре основные группы направленности критики: непосредственно на автора аккаунта, на проблему, которую он поднял в публикации, на действия властей в целом и на оппонентов, которые имеют отличную от комментатора позицию по теме публикации. Наибольшее количество направлено на волнующие и релевантные для потенциальных избирателей проблемы и больше характерно для политиков, открытых в социальных сетях и освещающих такие проблемы в своих публикациях.

Однако создание полноценного канала обратной связи с потенциальным электоратом положительно влияет на образ публичного политика, позволяет уменьшать количество обратной связи с негативным дискурсом и является успешной формой взаимодействия политика с электоратом и повышает его электоральный потенциал.

\section{Заключение}

Таким образом, из трех групп публичных политиков оказались готовыми к коммуникациям и наращиванию электорального потенциала в социальных сетях лишь главы российских регионов. Представители верхней палаты российского парламента имеют низкую степень присутствия в популярных социальных сетях и тем самым недоступны для потенциальных избирателей, а те, которые присутствуют, не ведут активной коммуникативной работы с подписчиками.

\section{Библиографический список}

1. Белоконев, С. Ю., Левина, Е. В. Теоретико-методологические аспекты изучения электорального потенциала публичных политиков и их позиционирование в социальных медиа // Гуманитарные науки. Вестник Финансового университета. 2021. - T. 11, № 2. - C. 47-55. https://doi.org/10.26794/2226-7867-2021-11-2-47-55

2. Коданина, А. Л. Социально-политические аспекты блогинга: российский опыт // Знак: проблемное поле медиаобразования. - 2017. - № 3 (25). - С. 177-182.

3. Комарова, А. А. Политические лидеры и молодежь: взаимодействие в социальных сетях // Цифровая социология. 2021. - T. 4, № 1. - C. 42-49. https://doi.org/10.26425/2658-347X-2021-4-1-42-49 
4. Крыштановская, О. В. Элита в сетях: новые формы обратной связи в цифровую эпоху // Цифровая социология. - 2019. T. 2, № 2. - C. 4-11. https://doi.org/10.26425/2658-347X-2019-2-4-11

5. Михайленок, О. М., Малышева, Г. А. Политические эффекты социальных сетей в России // Социологические исследования. - 2019. - № 2. - С. 78-87. https://doi.org/10.31857/S013216250004012-6

6. Попов, С. И., Ершов, Н. А. Политические коммуникации в интернете // Вопросы политологии. - 2018. - № 3 (31). - С. 28 -38.

7. Юшкина, Н. А., Панарина, М. А. Особенности дискурсивной среды как источник создания смысла в онлайн-коммуникации (на примере социальных сетей) // Цифровая социология. - 2019. - Т. 2, № 2. - С. 25-33. https://doi.org/10.26425/2658347X-2019-2-25-33

8. Hong, S., Nadler, D. Which candidates do the public discuss online in an election campaign? The use of social media by 2012 presidential candidates and its impact on candidate salience // Government Information Quarterly. - 2012. - V. 29, No. 4. Pp. 455-461. https://doi.org/10.1016/j.giq.2012.06.004

\section{References}

1. Belokonev S. Yu., Levina E. V. Theoretical and methodological aspects of studying public politics' electoral potential and their social media positioning, Humanities and Social Sciences. Bulletin of the Financial University, 2021, vol. 11, no. 2, pp. 47-55. (In Russian). https://doi.org/10.26794/2226-7867-2021-11-2-47-55

2. Kodanina A. L. Social and political aspects of blogging: Russian experience, Sign: problematic field of media education, 2017, no. 3 (25), pp. 177-182. (In Russian).

3. Komarova A. A. Political leaders and young people: interaction in social networks, Digital Sociology, 2021, vol. 4, no. 1, pp. 42-49. (In Russian). https://doi.org/10.26425/2658-347X-2021-4-1-42-49

4. Kryshtanovskaya O. V. Elite in social networks: new forms of feedback in the digital age, Digital Sociology, 2019, vol. 2, no. 2, pp. 4-11. (In Russian). https://doi.org/10.26425/2658-347X-2019-2-4-11

5. Mikhaylenok O. M., Malysheva G. A. Political effects of social networks in Russia, Sotsiologicheskie issledovaniya, 2019, no. 2, pp. 78-87. (In Russian). https://doi.org/10.31857/S013216250004012-6

6. Popov S. I., Ershov N. A. Internet political communications, Political science issues, 2018, no. 3 (31), pp. 28-38. (In Russian).

7. Yushkina N. A., Panarina M. A. Features of the discursive environment as a source for creating meaning in online communication (using the example of social networks), Digital Sociology, vol. 2, no. 2, pp. 25-33. (In Russian). https://doi.org/10.26425/2658347X-2019-2-25-33

8. Hong S., Nadler D. Which candidates do the public discuss online in an election campaign? The use of social media by 2012 presidential candidates and its impact on candidate salience, Government Information Quarterly, 2012, vol. 29, no. 4, pp. 455-461. https://doi.org/10.1016/j.giq.2012.06.004 